\title{
Outlandish Spelling System Invented by Indonesian Internet Society: The Case of Language Usage in Social Networking Site
}

\author{
Rizky Anugrah Putra ${ }^{1}$,Sulis Triyono ${ }^{2 *}$ \\ ${ }^{1}$ Applied Linguistics, Universitas Negeri Yogyakarta, Indonesia \\ ${ }^{2}$ Applied Linguistics, Universitas Negeri Yogyakarta, Indonesia \\ Corresponding Author: Rizky Anugrah Putra, E-mail:rizkyap.2016@gmail.com
}

\begin{tabular}{l} 
ARTICLE INFO \\
\hline Article history \\
Received: July 08, 2018 \\
Accepted: September 06, 2018 \\
Published: December 01, 2018 \\
Volume: 7 Issue: 7 \\
Advance access: October 2018 \\
Special Issue on Language \& \\
Literature \\
\hline
\end{tabular}

Conflicts of interest: None Funding: None

\begin{abstract}
Before having consistent alphabetic writing system, Bahasa Indonesia had encountered several developments in orthographic enhancement. Bahasa Indonesia need to be enhanced for several reasons such as to create national identity and also to provide an ideal spelling system. Orthography system helps the language user to associate the symbol, sound, and meaning. For those reasons, the spelling system is important in written language since most of information and knowledge are preserved in written form. As time passes, there is almost no barrier in human interaction since the distance is narrowed by the technology. To use it efficiently, the language users utilize their language to be shorter but it is easier to understand. However, it creates discrepancy in the orthography system which hinders the interlocutor to get the actual meaning of the written language. This article reveals an issue about orthography system which is made by internet society in which has unusual alphabetic spelling system. The peculiarity is caused by psychological and social factor which revert the spelling model to be identical to children (immature speech).
\end{abstract}

Key word: Spelling, Bahasa, Orthography

\section{INTRODUCTION}

As a lingua franca, Bahasa Indonesia (BI) is medium to unify the nation since Indonesia consists of 742 languages and 1340 tribes. For those reasons, Bahasa Indonesia becomes national identity. Bahasa had undergone several orthographic development and revision which was started from Van Ophuijsen's spelling system till enhanced spelling system which had been accepted based on presidential decree num. 57. Year 1972 (Karyati, 2016). Those spelling systems have their own characteristics which tell us that in Bahasa had several inconsistent orthographic elements. Under those circumstances, it had been revised.

There are several reasons which trigger the revision Bahasa Indonesia spelling system. The first is the impact of the development of science and technology that affect Bahasa Indonesia usage orally and in writing. When using technology, we employ special register. This unique register is called textese (Van Dijk, Van Witteloostuijn, Vasic, Avrutin, and Blom, 2016). This textese is non-standard written language which could be understood by certain community for example in Indonesian internet community often uses word 'woles' which stands for 'take it slow'. Acoustically, it sounds like 'slow' which is spelled backward. Moreover, Bahasa Indonesia needs to borrow lexical item from other language such as English since most of modern technology has no equivalent translation in Bahasa Indonesia. For example, 'computer' which is translated in Bahasa Indonesia as 'komputer'. In addition, this is the evidence that technology may change the orthography system.

The second factor is caused by dominant civilization in complex social structures and also policy maker. In colonialization era, Bahasa Indonesia employed Latin alphabet with 26 symbols. However, since Indonesia was colonized by Dutch, the spelling system was customized to be identical to the colonist language. Taeyoung (2016) confirmed that during colonial control of British and Dutch, Malay and Bahasa Indonesia spelling characteristics were invented based on orthographic systems which previously provided by European Linguist. For those reasons, the old spelling system was nearly similar to the Dutch. Vikør (1988) agreed that romanized spelling system (Ophuijsen's spelling system) which was implemented in Indonesia in 1901 was based on Dutch spelling.

The third, another cause of the revision in the Bahasa Indonesia spelling system is to make the language more efficient and easy to use. Moreover, the spelling system should have a grapheme-phoneme correspondence principle which is the ideal form of an alphabetic spelling system. 


\section{The Evolution of Bahasa Indonesia Spelling System}

As previously mentioned, the spelling system which is currently used is General Guidelines for Bahasa Indonesia Spelling (PUEBI - Pedoman Umum Ejaan Bahasa Indonesia). Previously, several spelling innovations had been implemented in Bahasa Indonesia. The impact of this spelling revision is several books and literary works which were published when the older spelling system was implemented should be revised and republished.

The revision also affects several linguistic elements such as lexical, phonological and semantic. For example, Mijianti (2018) stated that in 50's, researcher and scientist in Indonesia did not familiar with word 'riset' since they used 'penyelidikan' which stands for research. Consequently, the revision provides better translation for several words.

The development of Bahasa Indonesia spelling system spent more than a century which was started in 1901 till now. During the development, there were five spelling inventions and every spelling system was invented based on dissimilar reasons.

\section{a) Van ophuijsen's spelling system}

Before the colonial administration in the Indonesia archipelago, Malay language was written by using Jawi script. However, the modernizers preferred the romanized spelling system (Taeyong, 2016) which was used as authoritative orthography system. Erikha (2015) believed that there were several reasons behind the revision of Bahasa Indonesia spelling system. First, the Dutch administrators were agitated about Islamic community power since Jawi characteristics were based on Arabic spelling system. The Dutch administrators needed to reduce the Islamic influence in the Indonesian archipelago by romanizing the Jawi script. Second, it was a part of ethical politics. Third, it was language politics since Dutch linguist assumed that by standardizing the Bahasa Melayu might help the education process. In addition, the administrator utilized Bahasa Melayu to be lingua franca. For those reasons, the Dutch administrators appointed Ch. A. Van Ophuijsen who was a Bahasa Melayu linguist to standardize the language and to provide grammatical guide book entitled Woordenlijst Voor de Spelling der Malaisch taal met Latinjch (Mijianti, 2018). Later, the book was published in 1901 in Batavia.

In addition, the orthography system was labelled as Ophuijsen spelling system since it was the first romanized spelling system in Indonesia. It has several categories which are elaborated as follows:

a) It uses $<i>$ symbol to represent phoneme [i] which appears in final position or ultimate as a diphthong. For example, geraï dan cabaï. Moreover, it is also used to substitute the grapheme $<y>$ which often joins with other vowel to represent diphthong such as word $<$ pepaïa $>$.

b) The grapheme $<j>$ is also used to represent phoneme [i] in medial position. For example, kajang, sajang, etc.

c) The vowel digraph $<$ oe $>$ is used to represent phoneme [u]. For example: koetoe, soeroe, loeloes, etc.

d) The diacritic sysmbol such as $\langle$ ' $>$ is used to represent [?] (glottal stop) and [k]. For example: ka 'tus, ba 'so, ra', etc. e) The consonant digraph $<\mathrm{tj}>$ is used to represent [d]]. For example: tjitjak, tjat, ketjoa, etc.

f) The consonant digraph $\langle\mathrm{ch}\rangle$ is used to represent $\langle\chi\rangle$ (voiceless uvular fricative). For example: machloe', chatam, choetbah, etc.

\section{B) Republic spelling system (soewandi's spelling system)}

Republic spelling system was invented by Soewandi to reduce the influence of Dutch domination which was delineated in Ophuijsen's spelling system. Erikha (2015) confirmed that Soewandi's spelling system was officially used in 1947. There are several characteristics of Soewandi's spelling system which are elaborated as follows:

a) The vowel digraph $<$ oe $>$ is substituted with grapheme $<\mathrm{u}>$ in order to simplify the phonetic representation of phoneme [u]. For example: doeloe becomes dulu.

b) The glottal stop [?] is represented by grapheme [k]. Under this circumstance, the word such as ka toes in Ophuijsen's become kaktus in Soewandi's spelling system.

c) Reduplication is written by adding numeral symbol $<2>$. For example: kupu2.

d) There was no distinction in using inflectional suffix $d i$-. In other word, the suffix $d i$ - is not separated whether it acts as inflectional suffix or preposition.

e) The diacritic symbol is no longer used to represent schwa or [ə]. For this reason, the word such as képala is spelled as kepala in Soewandi's spelling system.

\section{c) Reformed spelling system}

Renewal spelling system or Ejaan Pembaharuan was developed since the minister of education of Indonesia, Moehammad Yamin worried about Bahasa Indonesia which did not have identity. Moreover, it still manifested the other spelling system element such as Dutch. Under those circumstances, Yamin proposed a revision for current spelling system which was not practical in the term of usage. To provide simple spelling system, the language development team employed one-to-one phoneme spelling system which is the fundamental principle of alphabetic writing system. However, this plan was not officially announced but later it was used as the fundamental reason of Bahasa Indonesia enhancement (Mijianti, 2018). The renewal spelling system has several characteristics which are elaborated as follows:

a) The consonant digraph $<$ ng $>$ is no longer used to represent [y] since in renewal spelling system $<\mathrm{n}>$ is directly used as one of alphabetic symbol.

b) The grapheme $<$ n $>$ is used to substitute $<$ nj $>$ which represents sound [n]. For example: njamuk becomes namuk.

c) The grapheme $<\breve{s}>$ is used to substitute $<$ sj $>$ which represents sound [J]. For example: sjukur become šukur.

d) The kinds of diphthong in Bahasa Indonesia which are [ai], [au], and [oi] are presented by using $<$ ay $>,<$ aw $>$, and $<$ oy $>$. 


\section{d) MELINDO spelling system}

Melindo spelling system is an orthographic combination between Indonesian alphabetic symbol rules and Persekutuan Tanah Melayu alphabetic system in 1957 (Mijianti, 2018). In 1957, Malaysia had earned their Independence, thus Prijono as the Minister of Education and Culture of Indonesia proposed to constitute intercultural affair between Indonesia and Malaysia (Taeyong, 2016). However, in 1960, the bilateral relationship between both nations became to depreciate since they had different ideology. Consequently, the implementation of Melindo spelling system was not materialized. In addition, there are several characteristics of Melindo spelling system, which are elaborated as follows:

a) The grapheme $<\mathrm{c}>$ is used to substitute consonant digraph $<\mathrm{tj}>$ which represent [t $\left.\int\right]$. For example: tjakar becomes cakar.

b) The diacritic in $<\mathrm{n}>$ is subtitited. Consequently, the it becomes $<\eta>$. For example: menyisir becomes menisir.

c) The consonant digraph $<$ nc $>$ is used to substitute $<$ nj $>$ which represent [d]]. For example: njanda becomes ncanda in Melindo.

d) The consonant digraph $<$ sy $>$ is used to substitute $<\breve{\text { s }}>$ which represents sound [C].

\section{e) Enhanced indonesian spelling system (ejaan yang disempurnakan).}

Enhanced Indonesian spelling system was invented based on agreement between the government of Indonesia and Malaysia. Therefore, in 1972, new spelling was officially used and dubbed as Enhanced Indonesian spelling system (Sebba, 2007 in Taeyong 2016). However, the development of Enhanced Indonesian spelling system underwent several phases in 1972, 1988, and 2009 (Mijianti, 2018). Every development phase of Enhance Indonesian spelling system has distinct characteristic. However, the current study only mentions the latest revision of enhanced spelling system which was dubbed General Guidelines of Indonesian spelling system by the new minister of education of Indonesia, Anies Baswedan. Based on regulation of ministry of education and culture, num. 50 2015, there are several characteristics of the latest Indonesian spelling system which is elaborated below: a) To distinguish the [e] and [ə] phoneme, the latest spelling system employs detailed diacritic symbols namely; 1) $<$ é $>$ to represent [e]; 2) <è $>$ to represent [3]; and 3) $<\hat{\mathrm{e}}>$ to represent schwa.

b) In the initial position, the grapheme $<x>$ represents [s].

c) The symbols $<$ ey $>$ which represents [eI] becomes $<$ ei $>$. For example: survey becomes survei.

Apart from several orthographic developments that have been noted above, many researchers are also aware that the impact of information technology can affect the use of language, especially orthography. Omar and Miah (2012) confirmed technologies and online information shape and reform modern spelling. People nowadays often substitute lexical element in sentences by using emoticon or emoji. Therefore, it is possible that in the future people might introduce 'new spelling' system which violates the rules since people love to follow new trends.
Table 1. The addition of grapheme $<\mathrm{h}>$ in the spelling alignment

\begin{tabular}{llll}
\hline Num. & Modified Spelling & EIS-System & Meaning \\
\hline 1. & kamuh & kamu & you \\
2. & mamah & mama & mother \\
3. & sayah & saya & I \\
4. & bencih & benci & hate \\
5. & rapih & rapi & tidy \\
\hline
\end{tabular}

Table 2. The insertion of grapheme $<y>$ in the spelling alignment

\begin{tabular}{llll}
\hline Num. & Modified Spelling & EIS-System & Meaning \\
\hline 1. & diya & dia & he/she \\
2. & kesepiyan & kesepian & loneliness \\
3. & kepergiyan & kepergian & departure \\
4. & Impian & impiyan & dream \\
5. & kaliyan & kalian & you \\
\hline
\end{tabular}

Table 3. The addition of grapheme $<$ wh $>$ in the spelling alignment

\begin{tabular}{llll}
\hline Num. & Modified Spelling & EIS-System & Meaning \\
\hline 1. & kamuwh & kamu & you \\
2. & akuwh & aku & I \\
3. & dirimuwh & dirimu & yourself \\
4. & selaluwh & selalu & always \\
5. & rapuwh & rapuh & fragile \\
\hline
\end{tabular}

Table 4. The grapheme $<\mathrm{c}>$ is used to substitute $<\mathrm{s}>$ in the spelling alignment

\begin{tabular}{llll}
\hline Num. & Modified Spelling & EIS-System & Meaning \\
\hline 1. & cemangat & semangat & spirit \\
2. & cayang & sayang & love \\
3. & celalu & selalu & always \\
4. & calah & salah & inaccurate \\
5. & carapan & sarapan & breakfast \\
\hline
\end{tabular}

Table 5. The grapheme $<\mathrm{g}>$ is used to substitute $<\mathrm{k}>$ in the spelling alignment

\begin{tabular}{llll}
\hline Num. & Modified Spelling & EIS-System & Meaning \\
\hline 1. & cweg & cewek & girl \\
2. & cueg & cuek & ignore \\
3. & anag & anak & children \\
4. & koreg & korek & matches \\
5. & tusug & tusuk & stab \\
\hline
\end{tabular}

However, the current study has reveal that there is regional orthographic invention which had been used in internet society, particularly teenager. The peculiarity in their writing is they often add an orthographic element 
in their 'status' in facebook or twitter which is considered as 'alay' or 'cheesy'. For example, the word sangat in Bahasa Indonesia is modified to be sangadh. The grapheme $<\mathrm{dh}>$ is used to substitute $\langle\mathrm{t}\rangle$ for certain reason. However, it still carries the original pronunciation and meaning. This orthographic spelling system is peculiar. For those reasons, only part of the community might easily decode the spelling. In addition, this phenomenon deteoriates the current spelling system which had been striven for a several decades.

Based on several justifications above, the present study wants to describe and reveal about the peculiar spelling system which made by netizen. The description relating how the symbol represent the phonological element and does the unofficial spelling system violate the basic principle of orthography writing system.

Table 6. The grapheme $<\mathrm{q}>$ is used to substitute $<\mathrm{k}>$ in the spelling alignment

\begin{tabular}{llll}
\hline Num. & Modified Spelling & EIS-System & Meaning \\
\hline 1. & $a q$ & $\mathrm{aku}$ & $\mathrm{I}$ \\
2. & qamu & kamu & you \\
3. & qeluarga & keluarga & family \\
4. & qwand & kawan & friend \\
5. & qelompok & kelompok & group \\
\hline
\end{tabular}

Table 7. The grapheme $<\mathrm{v}>$ is used to substitute grapheme $<\mathrm{b}>,<\mathrm{u}>$, and $<\mathrm{w}>$ in the spelling alignment

\begin{tabular}{llll}
\hline Num. & Modified Spelling & EIS-System & Meaning \\
\hline 1. & velajar & belajar & study \\
2. & mengvtak-atik & mengutak-atik & calibrating \\
3. & tavvoran & tawuran & riot \\
4. & vingsan & pingsan & fainted \\
5. & vavak & bapak & Mr. \\
\hline
\end{tabular}

Table 8. Consonant digraph implementation in netizen textese

\begin{tabular}{llll}
\hline Num. & Modified Spelling & EIS-System & Meaning \\
\hline 1. & bukandh & bukan & not \\
2. & sangadh & sangat & ignore \\
3. & cemangadh & anak & children \\
4. & iank & yang & matches \\
5. & saiank & sayang & stab \\
\hline
\end{tabular}

To accomplish the current study the research employed contrastive analysis to reveal and to describe the distinctive feature between of spelling system which is made by netizen and the current Indonesian spelling system. Further explanations are elaborated in following section.

\section{METHOD}

\section{Setting}

The present study focused on observing the use of Bahasa Indonesia, especially orthographic aspect which was done by social networking sites (SNS) users. There were several reasons why researchers chose social media, they are 1) because the source of data was already available without manipulation; 2) both data were readily available because not everyone voluntarily used the tacky language during communication; and 3) because there were several social groups and fans pages which made an unusual spelling trends. For this reason, researcher was interested in choosing SNS as a place to document the desired data.

\section{Procedure}

After obtaining the utterances expressed in written form by SNS users, researcher contrasted their spelling forms with acceptable spellings rules which is Enhanced Indonesian spelling system (Ejaan yang disempurnakan). Then, all forms of spelling violations were classified according to their characteristics in the form of tables or written descriptions. In addition, in order to preserve the identity and confidentiality of the SNS users, the researcher would not publish their utterances at all so that their status or tweet was solely used for analysis purposes.

\section{Analysis}

The analysis method used in this research was contrastive analysis which was also guided by other method such as orthographic distributional method. The researcher employed the additional method since the linguistic element which was observed is orthography. For those reason, the Enhanced Indonesian spelling system became the main parameter in the current research.

\section{RESULT}

The decent spelling should follow the rules which are prevailed and acceptable but in specific occasion, some the internet users, especially teenagers tended to modify the

Table 9. QDJY orthographic representation (vowels)

\begin{tabular}{llllll}
\hline Num. & QDJY spelling & EIS-System & Sound Representation & \multicolumn{2}{c}{ Example } \\
\cline { 4 - 6 } & & & QDJY & neeneeq & nenek \\
\hline 1. & $<\mathrm{ee}>$ & $<\mathrm{e}>$ & {$[\mathrm{e}]$} & peepaia & pepaya \\
2. & $<\mathrm{i}>$ & $<\mathrm{y}>$ & {$[\mathrm{i}]$} & oosoos & usus \\
3. & $<\mathrm{oO}>$ & $<\mathrm{u}>$ & {$[\mathrm{u}]$} & & os \\
\hline
\end{tabular}


Table 10. QDJY orthographic representation (Consonants)

\begin{tabular}{|c|c|c|c|c|c|}
\hline \multirow[t]{2}{*}{ Num. } & \multirow[t]{2}{*}{ QDJY spelling } & \multirow[t]{2}{*}{ EIS-System } & \multirow[t]{2}{*}{ Sound Representation } & \multicolumn{2}{|c|}{ Example } \\
\hline & & & & QDJY & EIS \\
\hline 1. & $<\mathrm{tj}>$ & $<\mathrm{c}>$ & {$[\mathrm{t} f]$} & tjaqar & cakar \\
\hline 2. & $<\mathrm{f}>$ & $<\mathrm{v}>$ & {$[\mathrm{f}]$} & fax & vas \\
\hline 3. & $<\mathrm{dj}>$ & $<\mathrm{j}>$ & [d] & djeedjaq & jejak \\
\hline 4. & $<\mathrm{k}>$ & $<q>$ & {$[\mathrm{k}]$} & kary & qari \\
\hline 5. & $<q>$ & $<\mathrm{k}>$ & {$[\mathrm{kw}]$} & qoorma & kurma \\
\hline 6. & $<\mathrm{s}>$ & $<\mathrm{sh}>$ & {$\left[\int\right]$} & sampo & shampo \\
\hline 7. & $<\mathrm{v}>$ & $<\mathrm{f}>$ & {$[\mathrm{f}]$} & vytnah & fitnah \\
\hline 8. & $<\mathrm{x}>$ & $<\mathrm{s}>$ & [s] & xeendjata & senjata \\
\hline 9. & $<y>$ & $<\mathrm{i}>$ & [i] & yqatan & ikatan \\
\hline
\end{tabular}

spelling that was materialized in their status in cyberspace. Indeed, the modification was peculiar and hard to accept by language community. Moreover, the researcher believed that the users modified the spelling since in their community it was acceptable and common.

The researcher found that many SNS users added grapheme $<\mathrm{h}>$ at the ultimate position. However, phonetically, the grapheme $<\mathrm{h}>$ does represent any sound. In addition, the researcher did not find similar spelling pattern which adds $<\mathrm{h}>$ but the researcher found that the users of this pattern are mostly teenager particularly female.

Similar to previous spelling form, the grapheme $<y>$ does not have sound-letter relationship. In other word, the researcher believes that it is silent letter. Moreover, it does not alter the word meaning and pronunciation. The researcher recognized that this pattern was only inserted in the word which has diphthong [ai].

The netizen added the grapheme $<$ wh $>$ in word which ends with sound $[\mathrm{u}]$. The researcher hypothesizes that $<\mathrm{wh}>$ does not represent any sound. For that reason, the researcher believes that this spelling form does not affect the pronunciation and meaning since it is still noticeable.

The netizen utilized grapheme $<\mathrm{c}>$ to substitute $<\mathrm{s}>$. Different from previous pattern, this pattern actually changes the pronunciation since it alters the sound [s] to be [t $\mathrm{f}]$. In addition, the researcher assumes that it is a kind of imitation of children's early vocalization in Bahasa Indonesia which often substitutes the grapheme $<\mathrm{s}>$ with $<\mathrm{c}>$ due to the incomplete set of articulatory organs. In addition, the researcher recognizes that the anomaly only occurs in the initial position.

The researcher found that the netizen used grapheme $<\mathrm{g}>$ to substitute $<\mathrm{k}>$. However, the alternation does not affect the pronunciation since the grapheme $<$ g $>$ actually still represents similar sound. In addition, this alternation only appears when grapheme $<\mathrm{k}>$ is located in the final position. Moreover, the researcher also found that $\langle\mathrm{gh}>$ was used to substitute $<\mathrm{k}>$. For example: enak becomes enagh.

In this orthographic pattern, the grapheme $<\mathrm{k}>$ which appears in initial position was changed into $<q>$. There was no phonological alternation since the sound representation remains the same which $<\mathrm{q}>$ represent $[\mathrm{k}]$.

The researcher obtained this orthographic pattern from memetic community. Netizens was used $<\mathrm{v}>$ to substitut- ed the grapheme $<\mathrm{b}>,<\mathrm{u}>$, and $<\mathrm{w}>$. However, serious orthographic problem occurs when word which has $<\mathrm{b}>$, $<\mathrm{u}>$, and $<_{\mathrm{w}}>$ was modified into this memetic spelling. Consequently, it creates outlandish spelling. For example, bubuk modified into vvvvk. For casual internet user which is not familiar with memetic community, the word $v v v v k$ does not have any meaning. This is the reason why spelling system sound adapt one-to-one correspondence between symbol-sound. The researcher realizes that the trend of $<_{\mathrm{V}}>$ spelling in memetic community of Indonesia was based on humorous purpose.

As can be seen in the table above, there are several complexities which was made netizen. First, they modified $<$ n $>$ to be $<$ ndh $>$. The $<$ ndh $>$ is considered as consonant trigraph since it consists of the combination of three grapheme which represent single segment or sound. Second, they substituted the grapheme $\langle\mathrm{t}\rangle$ to be $\langle\mathrm{dh}\rangle$. The grapheme $\langle\mathrm{t}\rangle$ and $<\mathrm{d}>$ represents [t] and [d] which shares similar place and manner of articulation. For this reason, the researcher believes that the netizen chose consonant digraph $<\mathrm{dh}>$ since it sounds identical to [ $\mathrm{t}$ ]. Third, they used $<$ nk $>$ to substitute $<$ ng $>$. However, it had been used in several Indonesian slang registers.

\section{QDJY Spelling System}

In addition, the researchers also identified a community that introduced their own Indonesian spelling system. This community is called REPOOBLYQ QDJY, which proposed unusual spellings. This community was founded by Sweta Kartika who was a graduated from Institut Teknologi Bandung (ITB). Sweta Kartika is an illustrator and comic artist. He claimed that REPOOLYQ QDJY which is spelled as Republik Keji in Enhanced Indonesian spelling system, is one of the intellectual development projects. Yet this is an ambitious but not serious project. Sweta often used QDJY's spelling to write or criticize the latest situation occurring in the country with a humorous style.

The QDJY spelling at a glance looks like using an old Indonesian spelling system but there are actually several combinations of other language orthography representations that have been applied in this spelling system. 
To represent vowel sound, QDJY spelling system has 3 unusual orthographic representation. QDJY employs vowel digraph to represent certain sound such as [i] and [u]. The researcher noticed that vowel digraph $<00>$ which substitutes $<\mathrm{u}>$ was modified based on English digraph representation. In English, vowel digraph $<\mathrm{oo}>$ represents $[\mathrm{u}]$ in stressed position. In addition, QJDY substitutes $<y>$ with $<\mathrm{i}>$. This representation model is based on Bahasa Indonesia phonographic.

Based on the table above, QDJY spelling system adapts the Ophuijsen's spelling system since it changes the grapheme $\langle\mathrm{c}\rangle$ and $\langle\mathrm{j}\rangle$ with $\langle\mathrm{tj}\rangle$ and $<\mathrm{dj}>$. Those consonant digraphs represent affricate sounds. However, in QDJY, the grapheme $<j>$ is not utilized to represent semivowel since if $\langle\mathrm{dj}\rangle$ represent [d]], the grapheme $\langle\mathrm{j}\rangle$ should represent semivowel. In other word, the QDJY developers employed Ophuijsen's spelling system partially.

In addition, in QDJY, the orthographic role of grapheme $<\mathrm{k}>$ and $<\mathrm{q}>$ is reversed. Consequently, the phoneme [kw] is represented by $[\mathrm{k}]$ and the phoneme $[\mathrm{k}]$ is represented by [q]. However, in Bahasa Indonesia, the occurrence of phoneme $[\mathrm{kw}]$ is fewer since most of the word which contains that sound is an Arabic loanword such as taklid. Moreover, the orthographic reversal also occurs between grapheme $<\mathrm{f}>$ and $\langle\mathrm{v}>$. Consequently, the word which uses grapheme $<\mathrm{v}>$ in EIS is changed into $<\mathrm{f}>$ in QDJY and vice versa.

To represent phoneme [J], QDJY spelling system uses consonant digraph $<_{\mathrm{S}}>$ which substitutes the grapheme $<$ sh $>$. Consequently, to represent [s], QJDY uses grapheme $<\mathrm{x}>$. These representation model is innovative but unusual since $<x>$ actually represent sound [3].

\section{DISCUSSION}

There are so many possibilities that cause the appearance of outlandish spelling. What the researcher believes is that this is one of the memetic phenomena in which a person culturally emulates a popular culture through imitation. What makes this phenomenon widespread is because of the nature of the idea itself that can take the form of attitudes, lifestyles, habits, etc., which are widely introduced and propagated in a culture or subculture community. In other words, researcher considers that this strange spelling as an Internet culture that continues to mobilize and evolve.

Then, as increasingly sophisticated technology causes these unusual spellings to spread more easily and affect the people who are exposed to them. With SNS that connects each individual from various regions, this is possible if there are modifications to the spelling based on certain factors.

\section{Technology Changes how we Spell}

In addition, Markub (2010) believed that one of factor which causes the unusual spelling occurs is the technology itself since when utilizing information and technology, users want to shorten the time by modifying the spelling. Based on Mphahlele and Mashamaite (2005), SNS users interact with other by modifiying symbols or spellings in order to save time and money efficiently. Thurairaj, Hoon, Roy, and Fong (2015) also agreed that SNS led their user to create new lexical element. They made the language shorter due to the effect of instant messaging system.

However, based on data which was found in this study proved that strange spelling does not make use written language more practical, it only made the language difficult to comprehend and to decode. At a glance, this phenomenon is similar to agraphia. Agraphia is a neurological disorder that causes a person to lose the ability to communicate in writing. One of the characteristics of agraphia is the loss of spelling ability.

However, the researcher found that those who produce this spelling were able to use good and correct spelling only in certain social conditions they usually changed the form of spelling. The use of this spelling sounds like a child's utterance that is usually called baby talk. This form of utterance is used by a mother to her child as a manifestation of the affectionate relationship between mother and child. Hermawan (2016) asserted that the use of strange spelling like this was caused by the psychological factors. This psychological disorder is referred to as psychogenic in which one uses language registers that sound immature or childish. The researcher believes that the spelling used tends to show the substitution of speech sounds which identical to the speech which existed in early children vocalization.

Kranjčić (2016) stated that this phenomenon is also labelled as infant-directed speech which are automatically used by adult when they are having interaction with children. Krashen (1981) mentioned that this modified language is intended to adapt infants' language competence since they still have low communicative competence. For this reason, it is possible that this phenomenon exists in written language since most of SNS provide written communication via chatting and messenger. The next question is why should use infant-directed speech in adult-to-adult interaction.

The speech disorder generally occurs in spoken language. The identifiable symptoms of a person suffering from this syndrome is that there is an inappropriate substitution of phonological structure in which the patient alters the sounds with other which acoustically identical to children who have not yet matured. Tanner (2008) believes that this is the most common form of immature speech which generally referred to as 'lisping'. Lisping usually occurs in children under 4 years old. An example of lisping in English is the substitution of interdental sound $[\Theta]$ which is replaced by sound [3] or [s]. For example, they become zey. In the Bahasa Indonesia, there is also a lisping phenomenon, but the sounds substitution that occur is different because in Bahasa Indonesia, the fricative [s] becomes affricate [c]. For example, the word sayang become cayang. The present study demonstrated that the lisping was also occurred in written communication. The SNS users changed the spelling which sound immature. However, the most of SNS user which were used this type of spelling were an adult female. Even though they are adults, the used immature speech to express their intimate relationship with their friend or they just wanted to be friendly with their friend list in the SNS.

\section{Lisping in Adult And Sexual Preference}

When observed the data from SNS, the researcher recognized that adult males were rarely used lisping. The research- 
er only found that adult males used lisping when they wanted to show their romantic relationship with their lovers. However, Tanner (2001) mentioned that if there is lisping in adult males, it indicates effeminate homosexuality. The researcher agrees with this statement since the researcher found that adult males who used lisping with their similar gender had unusual sexual orientation. However, in the present research, there is no scientific evidence about the frequency of lisping in homosexual community since they are prohibited in Indonesia. For that reason, the homosexual community in Indonesia is very closed and hidden because the Indonesian people are very critical of their sexual orientation which is considered to violate the religious norms and eastern culture. The researcher believes that lisping in adults were adjusted since they may spell correctly if they want. They imitated the immature spelling style to find comfort in social relationship (Tanner, 2008). Aronson (1990) also noted that lisping provides relief feeling which release its users from the adult responsibilities. Thereupon, speech disorder may not cause the spelling anomaly, but it is caused by social reasons.

\section{Immature Speech in Online Written Communication}

Lanchatin Lanchantin, Simoës-Perlant and Largy (2012) argued that there is no exact distinction between oral and written communication. On other word, it becomes vaguer. Shorter communication which mediates through SNS leads young adults to produce informal writing. Moreover, informal writing may appear from informal speech input since the primary medium of communication is oral. Then, the phonemes in oral communication are represented by using alphabet symbol. If one has produced peculiar spelling, it may resemble their speech since cognitively there is a relation between sound and symbol. Under this circumstance, it is obvious why their online post contains unusual spelling form.

\section{'Outlandish' Spelling Relates to Adolescence Psychology}

Adolescents is a transitional period from childhood to adulthood in which a person will grow to achieve mental, emotional, social, and physical maturity. Adolescents are very creative organisms, but their creativity tangible against the existing system (Barker, 2012). Comparatively, 'alay' spelling which is very commonly found in adolescents, it is considered as a manifestation of their resistance to the existing spelling system. This is the process of finding identity and fame by doing something different. They try to create a new language spelling system, which is considered creative. This is solely done to gain social attention and recognition. Under those circumstances, the article hypothesized that the users of 'outlandish' or 'alay' spelling come from adolescents' community.

\section{The Debate About the Netizen Spelling System}

Again, the researcher wishes to affirm that the language is arbitrary which takes form in, sound or symbol used by a particular social community. What is acceptable among them is something we cannot blame because the language is dynamic and will continue to grow. In addition, language is also an identity, therefore some groups make language modifications to be used as a special language of their community. In linguistic studies, opposing the phenomenon of language development in certain social environments is a mistaken thing because the diversity of language is the core of linguistic studies that uphold multilingualism. However, for those who counter with the presence of these unusual spellings, there is a solution that can be offered. One solution is to normalize the use of language in short message technology (Eisenstein, 2013). But the process of normalization would be a little inconvenient for users of chatting software because they prioritize the practicality than the structure.

Belal (2014) objected that bad spelling from social media provides negative influence since incorrect grammar and sentence structure in students writing can be affected by SNS. Nonetheless, SNS also has beneficial impact which was confirmed by Belal that SNS may help the students and also teacher to exchange ideas and to formulate group discussion. Thus, it depends on the student how they can utilize the SNS to help them improve their language competence. Mingle and Adams (2015) acknowledged that SNS may have negative impact on student academic performance if it is not used properly. They agreed that there are a lot of benefits abound in SNS such as sharing information, experiences, and ideas. In other word, the learning outcomes are affected by the decision of the students in using SNS.

\section{QDJY Spelling is an Intellectual Product}

People assume that QDJY spelling system popularized by Sweta Kartika is 'Bahasa Alay'. He confirmed in the article antaranews.com that this is a project which has rich intellectual elements. He asserted that in fact he tried to fight the culture of 'Bahasa Alay'. The current study realizes that to understand the spelling QDJY requires historical and linguistic knowledge of how the spelling system of Indonesian language develops because Sweta himself frankly adopted some of the Ophuijsen's spelling rules in his QDJY spelling system. The researcher is interested in the courage of Sweta who made this spelling system because he did not simply make it without any fundamental knowledge. Therefore, from the beginning QDJY spelling is not caused by psychological disorders but purely because it is merely intercultural projects.

\section{Potential Limitation}

The researcher is well aware that this article is far from perfect. On that basis, the researcher wanted to convey some of the shortcomings and limitations in this study. First, the researcher hasn't been able to bring the scientific evidence associated with a language disorder caused by neurological factors. Therefore, the present study did not provide records of operations or the results of a brain scan. In addition, researchers also focused on aspects of spelling in which the unusual spelling in Bahasa Indonesia is more easily found and accessed inside the SNS. 


\section{CONCLUSION}

The spelling evolution which is created by society is dynamic and cannot be avoided since it follows the language mobilization. The article suggests that the unusual spelling in Bahasa Alay was easier to be identified in adolescent. In their transitional period, adolescents invented their own spelling system as the manifestations of resistance of established rule. Moreover, peculiar spelling was found in adult which sounds similar to baby-talk or immature speech. The type of immature speech that they made was lisping which is phonologically similar to the baby talk. The researcher found there are two probabilities about lisping in adults. First, it may indicate psychogenic disorder. Second, it indicates someone with unusual sexual orientation.

\section{REFERENCES}

Aronson, A. (1990). Clinical voice disorders: An interdisciplinary approach. New York: Thieme

Barker, C. (2012). Cultural studies: Theory and practice. London: Sage.

Belal, A. (2014). Influence of digital social media in writing and speaking of tertiary level student. Thesis. Department of English and Humanities of BRAC University

Dijk, C. N., Witteloostuijn, M. V., Vasić, N., Avrutin, S., \& Blom, E. (2016). The influence of texting language on grammar and executive functions in primary school children. Plos One, 11(3). doi:10.1371/journal.pone.0152409

Eisenstein, J. (2013). What to do about bad language on the internet. Proceeding of NAACL-HLT, pages 359-369. Retrieved March 26, 2018, from https: http://www.aclweb.org/anthology/N13-1037

Erikha, F., \& Zenius Education. (2017). Edjaan tempoe doeloe hingga ejaan yang disempurnakan. Retrieved March 26, 2018, from https://www.zenius.net/blog/9959/sejarah-eyd-ejaan-bahasa-indonesia

Hermawan, N., F. (2016). Gangguan psikogenik orang 'alay'. El-Wasathiya: Jurnal Studi Agama, 4(2).

Karyati, Z. (2016). Antara EYD dan PUEBI: suatu analisis komparatif. Jurnal SAP, 1(1). Retrieved March 27, 2018

Kranjčić, T. (2016). Baby talk in adult-to-adult communication. Thesis. Filozofski fakultet u Zagrebu, Department of English Language and Literature

Krashen, S. (1981) Second language acquisition and second language learning. Oxford: Pergamon. http://dx.doi. org/10.1787/9789264230750-en
Lanchantin, T., Simoës-Perlant, A., \& Largy, P. (2012). The case of digital writing in instant messaging: when cyber written productions are closer to the oral code than the written code. PsychNology Journal, 10(3), 187-214

Markub. (2010). Penggunaan Bahasa alay. HUMANIS, 2(1).

Mijianti, Y. (2018). Penyempurnaan Bahasa Indonesia. Belajar Bahasa, 13(1).

Mingle, J and Adams, M., (2015).Social media network participation and academic performance in senior high schools in Ghana. Library Philosophy and Practice (e-journal). 1286. http://digitalcommons.unl.edu/libphilprac/1286

M. (2013, August 18). Sweta Kartika tidak sekadar bikin komik. Retrieved March 26, 2018, from https://www.antaranews.com/berita/391094/sweta-kartika-tidak-sekadar-bikin-komik

Mphahlele M.L. \& Mashamaite, K. (2005). The impact of short message service (sms) language on language proficiency of learners and the sms dictionaries: A challenge for educators and lexicographers. Proceedings of the IADIS Internasional Conference Mobile Learning 2005, 161

Omar, A. and Miah, M. (2012). Impact of technology on teens' written language. International Journal of Advanced Trends in Computer science and Engineering, 1(1).

Sebba, Mark, 2007. Spelling and society: the culture and politics of orthography around the world. New York: Cambridge University Press.

Taeyong,C. (2016). Differences in the romanized spelling of Arabic loanwords in Bahasa Melayu in Malaysia, and Bahasa Indonesia. Melayu: jurnal antara bangsa dunia melayu, 9(2).

Tanner, D.(2008). Speaker profiling persons with communication disorders. The Internet Journal of Forensic Science, $4(1)$.

Tanner, D. (2001). Hooray for hollywood: Communication disorders and the motion picture industry. ASHA Leader, 6(6).

Thurairaj, S., Hoon E.P, Roy S.S and Fong, P.K. (2015). Reflections of students language usage in social networking sites: making or marring academic English" The Electronic Journal of e-Learning, 163(4), (pp302-316) available online at www.ejel.org

Vikør, Lars S. (1988). Perfecting spelling: spelling discussions and reforms in Indonesia and Malaysia, 19001972. Dordrecht-Holland, Providence-USA: Foris Publications. 